ORIGINAL ARTICLE

\title{
Electronic Information Sources Access and Use for Healthcare Services in Governmental and Non-Governmental Hospitals of Western Oromia, Ethiopia: A Cross Sectional Study
}

\author{
Senait Samuel ${ }^{1}$, Getachew Bayissa ${ }^{1}$, Selam Asaminewu ${ }^{1}$, Tesfamichael Alaro ${ }^{2}$
}

ABSTRACT

BACKGROUND: Access to and use of electronic information sources for clinical decision is the key to the attainment of health related sustainable goals. Therefore, this study was to assess Electronic Information Sources (EIS) access and use for healthcare service among hospitals of Western Oromia, Ethiopia, 2013.

MATERIALS AND METHODS: A descriptive study design with quantitative and qualitative data collection methods was employed. Study subjects were selected by using simple random sampling technique. Quantitative data were entered and analyzed using SPSS version 16.0. Moreover, multiple logistic regression was fitted to identify independent predictors, and qualitative data were transcribed and analyzed thematically.

RESULTS: A total of 590 health professionals were participated in the study with response rate of $95 \%$. Forty-two percent of health professionals had used Electronic Information Sources (EIS). Out of them, more than half used to get latest health information. About three-fourth of health professionals had no formal training on how to use EIS. Moreover, there is a significant association between use of electronic information source and information literacy training, computer literacy level, access to internet connection and access to computers.

CONCLUSIONS: In this study, it was determined that more than half of health professionals in the study area were not using EIS. Information literacy training, self-stated computer literacy level, access to internet connection and access to computers with in hospitals were found to be statistically significant factors affecting use of EIS.

KEYWORDS: Electronic Information Source, Electronic Information Source use, Health

Professionals, Healthcare services

DOI: http://dx.doi.org/10.4314/ejhs.v26i4.6

\section{INTRODUCTION}

Healthcare is an information intensive activity. Hence, over the years, information related problems in the health sector have raised the concern of information professionals, health workers and social scientists (1). The rapid advancement in information and communication technology (ICT) and access to EIS provide new opportunity to bridge the gap (2).
Electronic information sources are defined by different scholars differently and commonly can be defined as sources of information that are held in a digital or electronic format. EIS can be accessed, searched or retrieved either by an electronic network or by an electronic data Processing application (3-5). Building up of quality, fast and effective service that supports the development will not be realized without effective and efficient utilization EIS. Electronic

\footnotetext{
${ }^{1}$ Department of Information Science, College of Natural Sciences, Jimma University, Jimma, Ethiopia

${ }^{2}$ Department of Health Economics, Management and Policy, College of Health Sciences, Jimma University, Jimma, Ethiopia
} 
Corresponding Author: Tesfamichael Alaro,Email:tesfamichaelalaro@yahoo.com /tesfamichaelalaro@ju.edu.et

information source has provided a wider access to global information resources such as online databases, e-journals, e-prints and other sources of digital information (4).

Accordingly, EIS has been found relevant to the health professionals to give quality and timely service $(6,7)$. EIS can improve workforce and workplace efficiency and boost quality of care by reducing medical errors, reducing costs and improving safety. They provide networks and tools for learning, research and practice (8).

Access to electronic information essentially includes access to electronic technologies (9). Moreover, access to and use of EIS is critical to the delivery of effective healthcare services. However, lack of access to and use of EIS remains one of the major barriers to the practice of evidence based medicine in low source settings (10-12). EIS creates access, enhances quality, improves healthcare interventions and can act as a solution for situations where human resources for health are scarce (8).

A systematic review of 38 and 23 studies from 1994 to 2009 as to why health professionals use the EIS discovered that their activities focus on the use of email, retrieving information from online journals, attending courses and conferences, receiving professional updates and performing professional and administrative functions $(13,14)$.

However, different studies conducted in different parts of Africa reported factors affecting use of electronic and digital information resources for better clinical decision making. These were lack of time, poor availability of broadband internet connection, lack of information searching skill, and cost of access (15-18).

A study conducted in Ethiopia in 2004 reported that all the hospitals use their computers for supporting their administrative and finance routines. A small proportion of the hospitals use computers for maintaining Electronic Patient Records (EPR). A significant percent of the hospitals use their computers for recording patient visits at the front desk, which they call reception of the hospitals. In hospitals with internet connection, the popular application used was sending and receiving E-mail messages. However, use of the internet for web browsing and electronic document searching was reported by more than half and $28.57 \%$ of the hospitals respectively (19). In Ethiopia, since 2005, special projects to promote the development and use of new electronic health content in multiple languages have been introduced. A significant challenge in providing multicultural electronic health content has been the limited awareness and use of ICT in general. The government has therefore taken positive actions to endorse and promote the use of ICT across all sectors (20).

Furthermore, Ethiopia is in the process of putting in place an E-health program to improve the delivery of healthcare services. The government also implemented a national plan for the development of ICT in health. Accordingly, a policy to reduce the costs of ICT infrastructure for the health sector has been implemented (21).

Giving quality health service is dependent upon the available information for health professional. Similarly, the World Health Organizations (WHO) encourages health professionals to access and use EIS for personal and professional growth. Educated and informed health work force would provide the best health services to populations worldwide and to achieve the best possible health for all. Furthermore, access to and use of EIS for clinical decision is the key to the attainment of health related sustainable development goals because information is vital for every endeavor (21). However, to the best of the investigators knowledge, there was no study conducted to explore the access and use as well as factors affecting use of EIS by focusing on both government and non-governmental hospitals. Thus, the present study was specifically dealing with assessment of the level of EIS access and use and factors affecting use of EIS among health professionals of Western Oromia governmental and non-governmental hospitals.

\section{MATERIALSAND METHODS}

The source population for this study was all health professionals in government and non-government hospitals. Samples of selected health professionals in hospitals of Western Oromia were the study population. A cross-sectional facility based descriptive study design was used to assess EIS access and use among health professionals in 
Governmental and Nongovernmental hospitals in Western Oromia.

The sample size was determined by using single population proportion formula and was found to be 620. The hospitals found in Western Oromia were categorized as governmental and non-governmental. From the total of 17 governmental hospitals, seven were selected randomly and one non-government hospital was selected purposively because it was the only one in the study area during the sudy period. The total sample was proportionally allocated to the categories. The governmental and nongovernmental category shares were again proportionally allocated to the respective hospitals based on the number of health professionals. Finally, share of each hospital was proportionally allocated to the type of professions. Moreover, sampling frame was prepared, and finally study subjects were selected by using simple random sampling technique. The quantitative data were collected using self-administered structured questionnaire adapted from different studies and modified to fit the local context. Additionally, indepth interviews with selected key informants (Medical directors of Hospitals) were conducted by using interview guide to collect qualitative data. Prior to data collection, ethical clearance was obtained from ethical clearance committee of Jimma University.

Statistical analysis: The collected data were coded, entered into a database and cleaned for any inconsistencies and missing values using SPSS version 16.0 statistical software. Uni-variate descriptive statistics were worked out. Moreover, multiple logistic regression was fitted to identify independent predictors of use of EIS. Confidence interval of $95 \%$ and P-value less than 0.05 was used to judge statistical significance. The qualitative data from in-depth interview was transcribed and analyzed thematically.

\section{RESULTS}

From the total of 620 sampled health professionals from government and non-government hospitals, 590 participated in the study with response rate of
95\%. Of them, 565(95.8\%) and $25(4.2 \%)$ were from governmental hospitals and private hospitals respectively. Three hundred seventy-five $(63.6 \%)$ of the health professionals were male. The mean age of respondents was $30.75 \pm 7.02$ years.

\section{Access to and Use of Computers and Electronic Information Sources}

Access to Computers: Out of the total respondents, $139(23.6 \%)$ had access to computers within hospitals. Within nongovernmental hospitals, $84 \%$ of health professionals access computers whereas within governmental hospitals $20.9 \%$.

Place where accessing electronic information sources: Out of the total of 590 respondents, $303(58 \%)$ access EIS from internet cafe while $18.0 \%$ access from hospitals. Concerning access to internet connection, 436(73.9\%) of health professionals have no access at all.

Exposure to computers: Concerning level of computer literacy more than half of the respondents were below average, and $7.97 \%$ had average computer literacy (see Figure 1 below).

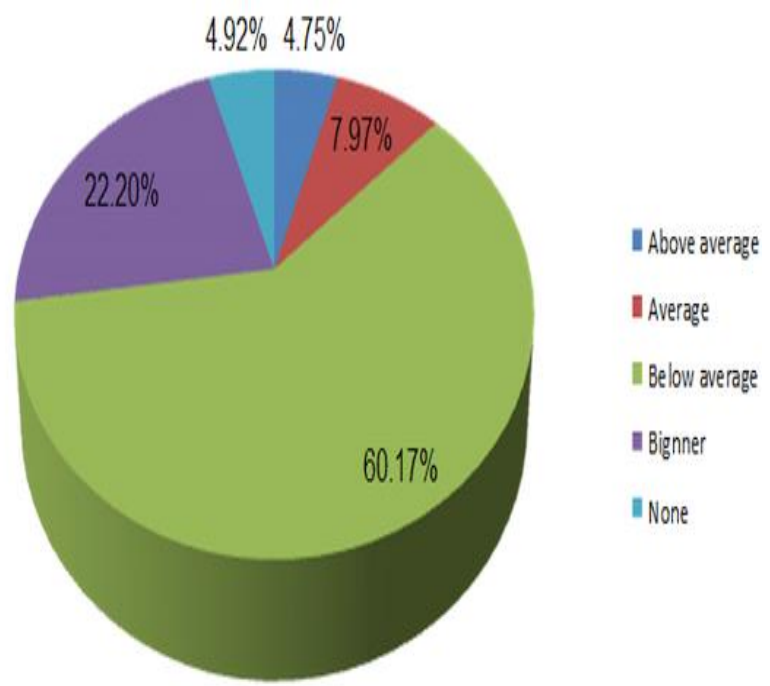

Figure 1: Level of computer literacy of health professionals in Western Oromia hospitals of Ethiopia $(N=590)$ 
Table1: Socio-demographic characteristics of Health professionals in Hospitals of Western Oromia, Ethiopia, April 2013 (N=590).

\begin{tabular}{|c|c|c|c|c|}
\hline Characteristics & Response & $\begin{array}{l}\text { Governmental Hospital } \\
\text { No }(\%)\end{array}$ & $\begin{array}{l}\text { Non-governmental } \\
\text { Hospital No }(\%)\end{array}$ & $\begin{array}{l}\text { Total No } \\
(\%)\end{array}$ \\
\hline \multicolumn{5}{|l|}{ Sex } \\
\hline & Male & $358(95.5)$ & $17(4.5)$ & $375(63.6)$ \\
\hline & Female & 207(96.3) & $8(3.7)$ & $215(36.4)$ \\
\hline Total & & $565(95.8)$ & $25(4.2)$ & $590(100)$ \\
\hline \multicolumn{5}{|l|}{ Marital status } \\
\hline & Never married & $259(95.2)$ & $13(4.8)$ & $272(46.1)$ \\
\hline & Currently married & $277(95.8)$ & $12(4.2)$ & $289(49.0)$ \\
\hline & Divorced/separated & $20(100)$ & 0 & $20(3.4)$ \\
\hline & Widows & 9 & 0 & $9(1.5)$ \\
\hline Total & & $565(95.8)$ & $25(4.2)$ & $590(100)$ \\
\hline \multicolumn{5}{|c|}{ Ethnic belongingness } \\
\hline & Oromo & $415(95.6)$ & $19(4.4)$ & $434(73.6)$ \\
\hline & Amhara & $80(98.8)$ & 1 & $81(13.7)$ \\
\hline & Tigre & $36(100)$ & 0 & $36(6.1)$ \\
\hline & Others* & $34(87.2)$ & $5(12.8)$ & $39(6.6)$ \\
\hline Total & & $565(95.8)$ & $25(4.2)$ & $590(100)$ \\
\hline \multicolumn{5}{|l|}{ Religion } \\
\hline & Orthodox & $166(94.9)$ & 9 & $175(28.5)$ \\
\hline & Protestant & $266(95.3)$ & $13(4.7)$ & $279(47.3)$ \\
\hline & Muslim & $83(97.6)$ & 2 & $85(14.4)$ \\
\hline & Catholic & $50(98.0)$ & 1 & $51(8.6)$ \\
\hline Total & & $565(95.8)$ & $25(4.2)$ & $590(100)$ \\
\hline
\end{tabular}

*include Gumuz, Wolaita and Gurage

Awareness of electronic information sources: Out of the total 590 health professionals in governmental and non-governmental hospitals, $561(95.1 \%)$ respondents ever heard of email whereas 251(42.5\%) also ever heard of different search engines (see Table 2 below).

Use of electronic information sources: Of the total respondents, $41.9 \%$ use EIS. From those using it, 231(95.5\%) and 11(4.5\%) were from governmental and non-governmental hospitals. Out of 242 respondents who use EIS, the majority used resources from internet cafe.

This was supported by a medical director interviewee as follows: Since it was a government direction to implement electronic
Health Management Information System (eHMIS) for better patient data handling and reporting: "we have audio-visuals (CDs/ DVDs) and we have planned to start internet/web services." Another medical director said "I use internet/ web from internet cafe to get latest health information, electronic mailing and entertainment." 
Table 2: Awareness of electronic information sources among Health professionals in Hospitals of Western Oromia, Ethiopia, April 2013 (N= 590)

\begin{tabular}{|c|c|c|c|c|}
\hline Characteristics & Response & $\begin{array}{l}\text { Governmental Hospital No } \\
(\%)\end{array}$ & $\begin{array}{l}\text { Non-governmental Hospital No } \\
(\%)\end{array}$ & $\begin{array}{l}\text { Total No } \\
(\%)\end{array}$ \\
\hline \multicolumn{5}{|c|}{ Ever heard of Internet/ Web } \\
\hline & Yes & $530(93.8)$ & $25(100)$ & $555(94.1)$ \\
\hline & No & $35(6.2)$ & 0 & $35(5.9)$ \\
\hline Total & & $565(100)$ & $25(100)$ & $590(100)$ \\
\hline \multicolumn{5}{|c|}{ Ever heard of Electronic journal } \\
\hline & Yes & $303(53.6)$ & $16(64.0)$ & $319(54.1)$ \\
\hline & No & $262(46.4)$ & 9 & $271(45.9)$ \\
\hline Total & & $565(100)$ & $25(100)$ & $590(100)$ \\
\hline \multicolumn{5}{|c|}{ Ever heard of Search engines } \\
\hline & Yes & $234(41.4)$ & $16(64.0)$ & $251(42.5)$ \\
\hline & No & $331(58.6)$ & 9 & $339(57.5)$ \\
\hline Total & & 565 & $25(100)$ & $590(100)$ \\
\hline \multicolumn{5}{|c|}{ Ever heard of Email } \\
\hline & Yes & $537(95.0)$ & $24(96.0)$ & $561(95.1)$ \\
\hline & No & $28(5.0)$ & 1 & $29(4.9)$ \\
\hline Total & & $565(100)$ & $25(100)$ & $590(100)$ \\
\hline \multicolumn{5}{|c|}{ Ever heard of Audio-Visual/DVD, CD } \\
\hline & Yes & $530(93.8)$ & $25(100)$ & $555(94.1)$ \\
\hline & No & $35(6.2)$ & 0 & $35(5.9)$ \\
\hline Total & & $565(100)$ & $25(100)$ & $590(100)$ \\
\hline \multicolumn{3}{|c|}{$\begin{array}{l}\text { Purpose of using electronic information } \\
\text { sources: Regarding purpose of using EIS, out } \\
\text { of } 242 \text { respondents, } 140(57.9 \%) \text { get latest health } \\
\text { information followed by } 35(14.5 \%), 27(11.2 \%) \text {, } \\
23(9.5 \%) \text { and } 17(7.0 \%) \text { for entertainment, } \\
\text { research, teaching and other purposes } \\
\text { respectively. }\end{array}$} & \multicolumn{2}{|c|}{$\begin{array}{l}\text { Importance and familiarity to Electronic } \\
\text { Information Source: Out of } 242 \text { respondents } \\
\text { who used EIS, } 234(94.4 \%) \text { found health } \\
\text { information located useful for their clinical } \\
\text { practice. Out of the total } 590 \text { respondents, } \\
340(57.6 \%) \text { rated the importance of EIS as high } \\
\text { Concerning familiarity with EIS, } 406(68.8 \%) \text { of } \\
\text { the respondents were unfamiliar with EIS (see } \\
\text { Table } 3 \text { below). }\end{array}$} \\
\hline
\end{tabular}

Table 3: Importance and familiarity to electronic information sources among Health professionals of Western Oromia, Ethiopia, April 2013 (N=590). 


\begin{tabular}{llll}
\hline Characteristic & Response & no & Percent (\%) \\
\hline Importance of electronic information sources & High importance & 340 & 57.6 \\
& Somewhat importance & 165 & 28 \\
& Little importance & 53 & 9 \\
& No importance & 15 & 2.5 \\
& Don't know & 17 & 2.9 \\
& Total & 590 & 100 \\
& Very Familiar & 12 & 2 \\
& Familiar & 82 & 13.9 \\
& Unfamiliar & 406 & 68.6 \\
& Very unfamiliar & 90 & 15.3 \\
& Total & 590 & 100 \\
\hline
\end{tabular}

Purpose and Frequency of using Computers: Regarding frequency of use, 181(35.8\%) of respondents used computers daily and $131(25.9 \%)$ them reported 4 to 5 times weekly. Concerning the purpose of use, $207(40.91 \%)$ and $161(31.7 \%)$ responded that they use computers to store and retrieve electronic patient information and to record patient visits respectively. The remaining $22.7 \%$ and $4.63 \%$ use computers for administrative and finance service purpose respectively. This was supported by the following qualitative data. A medical director of government hospital in-depth interviewee said: "There were 24 computers in our hospitals. Of this we use 19 computers for storing and retrieving patient information and the remaining to finance routines". Another non-government hospital medical director said: "I knew our hospitals had 28 computers of which we use only 3 for administrative purpose and the remaining for clinical care and to handle information related with patients for better clinical decisions".

Out of 84 health professionals who did not use computer, 39(46.4\%) reported lack of computer literacy/ICT skills, 26(31\%) had no computer accessibility and $19(22.6 \%)$ had no library in hospitals as barriers for using computers. Concerning barriers to the use of EIS, 299(50.68\%) of the respondents indicate lack of computer literacy/ICT skills as an obstacle.

This was supported by data obtained from indepth interview with a medical director who said: "I think the main barrier for the use of EIS is lack of information literacy for employees. Beside to this, in the organizational structure of hospitals there is no position for ICT professionals. However, due to current initiative to start electronic HMIS we have two ICT officers". Similarly, this was supported by data from in-depth interview in which a medical director said: "I am happy because within few months of two ICT officers employment, problems related with patient data handling and reporting were solved" (see Figure 2 below).

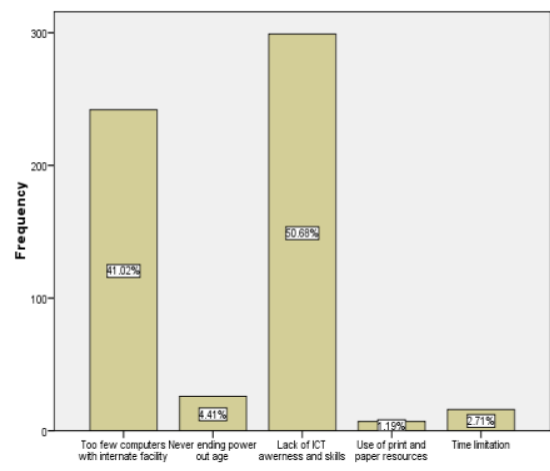

Figure 2: Barriers to use electronic information sources among Health professionals in western Oromia, Ethiopia, April 2013 ( $\mathrm{N}=590)$ 
Training on use of electronic information sources: Eighty-three percent of the respondents reported that they received no information literacy training on utilization of EIS. Moreover, this was supported by the medical director of a hospital who said: "...I have been working in this hospital for the last 4 years as medical director, but I haven't participated in information literacy training".

Out of the total 590 respondents, $302(51.2 \%)$ agreed that their activities would suffer without EIS. Regarding satisfaction level of respondents with access to EIS, 238(40.5 \%) were highly dissatisfied followed by $226(38.3 \%)$ who expressed dissatisfaction. Two hundred fifty- eight $(43.7 \%)$ reported that their hospitals had computer aided medical instruments attached to personal computer. This was also true for 235(90.1\%) governmental hospital and $23(8.9 \%)$ non-governmental hospital professionals.

This was supported by a medical director interviewee who said: "We have medical instruments attached to personal computers at different departments; like Complete Blood Count machine, Digital ultrasound and $x$ - ray machine which registers information digitally." Another medical director from non-government Hospital said "...I use digital ultrasound which is attached to personal computer to diagnose and treat patients".

Factors affecting use of electronic information sources: To further investigate the factors affecting use of EIS, variables like information literacy training, computer literacy training, access to computers, access to internet connection and other socio-demographic variables were analyzed by using multiple logistic regression analysis.

Accordingly, it was found that health professionals who had self-reported computer literacy level of below average were 0.277 times less likely to use EIS as compared to those who reported average computer literacy level $(\mathrm{AOR}=$ $0.227,95 \% \mathrm{CI}=0.082,0.624)$. The information literacy training was also found to be a determinant factor of EIS use. Health professionals who had information literacy training were 3.536 times more likely to use EIS as compared to their counterparts $(\mathrm{AOR}=3.536$, $95 \% \mathrm{CI}=2.250,5.558)$. Computer access at hospital was also found to be associated with the use of EIS $(\mathrm{AOR}=2.98,95 \% \mathrm{CI}=1.99,4.33)$. Furthermore, respondents who had access to internet connection were 2.431 times more likely to use EIS as compared to those who had no access to internet connection $(\mathrm{AOR}=2.431,95 \%$ $\mathrm{CI}=1.372$, 4.307) (see Table 4 below).

Table 4: Multiple logistic regression analysis of factors affecting use of electronic information sources among health professionals of Western Oromia, Ethiopia, 2013 G.C

\begin{tabular}{|c|c|c|c|}
\hline \multirow[t]{2}{*}{ Variables } & \multicolumn{2}{|c|}{ Use of electronic information sources } & \multirow[t]{2}{*}{ AOR $(95 \%$ CI $)$} \\
\hline & yes & No & \\
\hline \multicolumn{4}{|c|}{ Access of computers with in hospitals } \\
\hline No (ref) & 60 & 301 & 1 \\
\hline Yes & 85 & 157 & $2.98(95 \% \mathrm{CI}=1.99,4.33)$ \\
\hline \multicolumn{4}{|c|}{ Self-stated computer literacy } \\
\hline average (ref) & 30 & 17 & 1 \\
\hline Above average & 8 & 20 & \\
\hline Below average & 168 & 187 & $0.227(95 \% \mathrm{CI}=0.082,0.624)$ \\
\hline Beginner & 36 & 95 & \\
\hline None & 0 & 29 & \\
\hline \multicolumn{4}{|c|}{ Information literacy training } \\
\hline No (ref) & 175 & 314 & 1 \\
\hline Yes & 67 & 34 & $3.536(95 \% \mathrm{CI}=2.250,5.558)$ \\
\hline \multicolumn{4}{|c|}{ Access to internet connection } \\
\hline No (ref) & 105 & 228 & 1 \\
\hline Yes & 137 & 121 & $2.431(95 \% \mathrm{CI}=1.372,4.307)$ \\
\hline
\end{tabular}


N: B $95 \%$ CI was used to judge statistical significance

\section{DISCUSSION}

This study revealed that only $23.6 \%$ of the health professionals had access to computers in their hospitals. This finding is lower than the findings of a studies conducted by Wium and Naudé in South Africa, Pretoria, and Nurjahan, Lim and Yeong in Malaysia, which revealed that almost all health professionals had access to computers within their work environment $(22,23)$. The possible explanation for the observed discrepancy might be contextual difference in both locations. However, the finding is comparable with the finding of a study done in hospitals in Ethiopia in 2004 where 33\% of health professionals had access to computers in hospital. This study showed that $60.2 \%$ of the respondents had below-average computer knowledge. This finding is in line with a survey conducted in Ethiopia among health professionals where $65 \%$ had minimal computer knowledge $(10,19)$.

Quick access to computers and EIS was one of the necessities of health professionals for better clinical decision. In this regard, the use of EIS as a valuable tool plays an important role in provision of care to patients. It may also enhance health professionals' knowledge and Lifelong learning (24).

Health professionals' use of EIS has the potential to improve patient care $(25,26)$. However, in this study more than half of health professionals were not using EIS. This finding is in line with study conducted by Revereet et al (27).

This study unveiled that $10.33 \%$ and $39.26 \%$ of the health professionals used email and internet/web respectively. The finding is inconsistent with the findings by Zolfo et al and Ajuwon that revealed that the majority of health professionals had access to the web/internet and that almost all of them had their own email accounts $(10,18)$. The difference might be because this study was conducted in both governmental and non-governmental hospitals. However, it was in line with the study conducted in Malawi that indicated few professionals had access to internet facilities.
This study also showed that the majority used EIS from internet café. In the in-depth interview, a medical director said... "I use internet/web from internet café to gate latest health information, for electronic mailing and entertainment". This was similar with a study conducted by Ajuwon that reported more than half used EIS from internet cafe (18).

Concerning the purpose of use, in this study, around half and one-fourth of the health professionals mentioned that they used computers to store and retrieve electronic patient information and to record patient visit respectively. This finding was supported by qualitative data in that a medical director said: "I knew our hospitals had 28 computers of which we use only 3 for administrative purpose and the remaining for clinical care and to handle information related to patients for better clinical decisions".

This is comparable with studies undertaken by Lundeen and Fikre Yohannes that reported one third of studied health professionals used computers to access medical information, maintain Electronic Patient Records (EPR) and for recording patient visits at the front desk $(19,28)$.

This study also uncovered that more than half of the health professionals used EIS to get latest health information which support their clinical decision. This finding was to some extent in line with a systematic review of 38 studies by Masters from 1994 to 2004, by Dorsch and Younger. They reported health professionals use EIS to gather health information, continuing professional development, email, attending courses and conferences, and performing professional and administrative functions (13,14, and 17).

This study showed that out of respondents who used EIS, almost all found health information retrieved useful. This finding is congruent with the finding of a survey conducted by Prendiville, Saunders and Fitzsimons (6).

In this study, half of the health professionals indicated lack of computer literacy/ICT skills as a barrier for using EIS. This was supported by qualitative data obtained from a medical director who said: “... I think the 
main barrier for the using of EIS in our hospital is lack of computer literacy/ICT skills for employees". The finding was in line with a study conducted by Rehman and Ramzy in 2004 (16).

The present study showed that more than three-fourth of the health professionals had no information literacy training on utilization of EIS. However, health professionals who had information literacy training were 3.536 times more likely to use EIS as compared their counterparts. Similarly, the finding was supported by data obtained from a medical director who said: "I have been working in this hospital for the last 4 years as medical director, but I haven't participated in information literacy training”. This finding was higher than the finding of a study conducted by where, around half of the studied employees obtained training regarding the most effective use of information technology (17). Since, the study was crosssectional; it did not show cause and effect relationship between the predictor and outcome variables.

In this study, it was determined that more than half of the health professionals in the study area were not using EIS. Moreover, there was a statistically significant association between use of EIS and accesses of computer in hospital, computer literacy/ICT skill, information literacy training and accesses to internet connection. Hence, policy makers both at federal and regional level should devise strategies for successful and sustainable utilization of EIS by focusing on the aforementioned factors.

\section{ACKNOWLEDGEMENTS}

The authors would like to thank all of the participants of the survey for sharing their genuine personal experience. We extend our gratitude to Jimma University for funding the research.

\section{REFERENCES}

1. Musoke MGN. The Effect of Information on Primary Health Care: Examples from Rural Uganda. An Interdisciplinary Journal on Humans in ICT 2009; 5(2): 181-207.

2. Podichetty VK, Booher J, Whitfield M and Biscup RS. Assessment of Internet Use and Effects Among Healthcare Professionals: A
Cross sectional Survey. Postgrad Med J 2006;2(27): 4-279.

3. Horton R. North And South: Bridging the Information Gap. Lancet London 2000, 355 (9222):2231-6.

4. Vital Wave Consulting: eTransform Africa: Health Sector Study 2012.

5. Borycki EM, Kushniruk AW. Advances in Information and Communication Technology in Health. ISO press 2008, BV. doi:10.32.33/978-1-58603-979-0-3.

6. Prendiville TW, Saunders J and Fitzsimons $\mathrm{J}$. The Information-Seeking Behaviour of Paediatricians Accessing Web-Based Resources.Pub med 2009;94: 633-635. doi:doi:10.1136/adc.2008.149278.

7. Iva Seto, Michelle Foisy Brad Arkison, Terry Klassen, and Katrina Williams. The evaluation of an evidence-based clinical answer format for pediatricians. BMCPediatr 2012, 12: 34.

8. Dzenowagis J. Bridging the Digital Divide: Tele-health In Developing World. Royal Society of Medicine Press London 2009:925.

9. Gashaw K. Factor Affecting Access to Electronic Information and Their Implication. Idea Group Inc 2007

10. Zolfo M, Renggli V, Koole O and Lynen L. Telemedicine in Low-Resource Settings: Experience with a Telemedicine Service for HIV/AIDS Care. Southeast Asian J Trop Med Public Health 2005;36 : 1272-1274.

11. Gatero GM. Utilization of ICTs for Accessing Health Information by Medical Professionals in Kenya: A Case Study of Kenyatta National Hospital. Journal of Health Informatics in Developing Countries 2010.

12. Marker $\mathrm{P}, \mathrm{McNamare} \mathrm{K}$ and Wallance $\mathrm{L}$. The Significance Of Information And Communication Technologies For Reducing Poverty. London, UK: DFID 2002.

13. Masters K. For What Purpose and Reasons Do Doctors Use The Internet: A Systematic Review.International Journal of Medical Informatics, 2008;77(1): 4-16.

14. Younger P. Internet-Based InformationSeeking Behavior Amongst Doctors And Nurses: a Short Review Of theLiterature.Health Information and 
Libraries Journal 2010;27:2-10 doi:10.1111/j.1471-1842.2010.00883.

15. Bello I S. and Arogundade FA. Knowledge and Utilization of Information Technology among HealthCare Professionals and Students in Ile-Ife, Nigeria: A Case Study of a University Teaching Hospital. The Leading e-Health Journal 2004;4 (6):30-38.

16. Rehman SU and Ramzy V. Awareness and Use of Electronic Information Resources at the Health Sciences Center of Kuwait University. Library Review 2004;53(3): 150-156.

17. Dorsch JL. Information Needs of Rural Health Professionals: A Review of the Literature. Bull Med LibrAssoc 2000.

18. Ajuwon GA. Use of the Internet for health information by physicians for patient care in a teaching hospital in Ibadan. Biomedical Digital LibrariesNigeria 2006;3:12.

19. Fikreyohannes L, Samuel K and Solomon A. Survey of Current Efforts and Potentials in Application of Telemedicine in Ethiopia. Addis Ababa University 2004.

20. World Health Organization: Working Together For Health: Geneva 27, Switzerland. WHO Press 2007.

21. World Health Organization African Region: Building Foundations for e-Health. World Health Organization 2006.

22. Wium.AM and Naudé.E: Health Workers Use of Electronic Information Concerninig Children with Specific Communication
Needs. HEALTH SA GESONDHEID 2004, 9(2).

23. Nurjahan MI, Lim TA and Yeong SW. Utilization of Information Technology in Medical Education: A Questionnaire Survey Of Students in a Malaysian Institution.Med $J$ Malaysia 2002; 57: 58-66.

24. Jamshidi A, Mehrdad b AG and Jamshidi S. Assessing Nursing Students' Knowledge and Attitudes about Computers and the Internet. Elsevier Ltd. 2012; 46: 1371 1374.

25. Magrabia F, Coieraa EW, Westbrooka JI, Goslingb A.S and Vicklanda.V. General Practitioners' Use of Online Evidence during Consultations. Elsevier Ireland Ltd 2004.

26. Westbrook JI, Gosling AS and Coire PE. Do Clinicians Use Online Evidence to Support Patient Care? A Study of 55,000 Clinicians. Journal of the American Medical Informatics Association 2004;11(2):113120.

27. Revere.D,Turner.AM,Madhavan.A,Rambo. N,Bugni.PF,Kimball.A and Fuller.SS: Understanding The Information Needs Of Public Health Practitioners: A Literature Review To Inform Design Of An Interactive Digital Knowledge Management System. Journal of Biomedical Informatics 2007; 40: 410-421.

28. Lundeen.GW: Information Needs of Rural Health Care Practitioners in Hawaii. Bull Med LibrAssoc 1994, 82(2):197-205. 